\title{
A New Interface Detection Method Based on Heat Transfer Rate of Oil and Water
}

\author{
Kuijiang LIU 1,a , Guoying ZHANG ${ }^{1, a}$, Wei ZHANG ${ }^{1, a}$, Jizhi ZHANG ${ }^{1, a}$ \\ ${ }^{1}$ Dept of Computer Science and Technology, China University of Mining \& Technology, Beijing, \\ 100083, China
}

aemail: zhangguoying1101@163.com

\section{Key words: Interface detection; Heat transfer rate; Heat conduction; Heat convection}

\begin{abstract}
The detection of interface between water and oil is of great significance for the heavy oil exploitation. However, the existing detection techniques have some drawbacks, such as poor efficiency and low accuracy. A new interface detecting method based on the Heat Transfer Rate between oil and water is proposed. Heat transfer model including heat conduction and convection has been established in the paper. The computation method of Heat Transfer Rate is based on differential equation of Heat transfer model. Experiments of the thermal conductivity of oil and water were carried out under constant temperature condition. Experimental result shows that the heat transfer rate of water is much greater than that of heavy oil at different temperatures. And the different of heat transfer rate between oil and water can be used for the interface detection.
\end{abstract}

\section{Introduction}

Oil is one of the most crucial energy sources in the world, and detection of oil-water interface is a very significant technical problem in the process of oil production. Due to the high viscosity of the heavy oil, its flow resistance is very high. The traditional differential pressure or buoyancy method is not suitable for heavy oil interface monitoring. Capacitance measurement may obtain a small amount of sampling data, and detecting data has on low reliability [1]. The separation process of heavy oil and water needs to be heated to about $75^{\circ} \mathrm{C}$. The transfer heat of the oil and water after be heated mainly include heat convection and heat conduction. The heat flux of heat convection is significant difference from that of heat conduction, which leads to the difference of heat transfer rate. Heat transfer rate of oil and water was measured by a platinum resistance temperature sensor. The oil water interface can be detected through distinguishing the heat transfer rate between heavy oil and water.

\section{The heat transfer model of heavy oil and water}

After being heated up to about $75^{\circ} \mathrm{C}$, oil water mixture in the constant temperature storage tanks can be separated through gravity separation. The mechanism of heat transfer between different fluids or between the fluid and the solid wall is very complicated. When the fluid is in a static state or in a laminar flow, generally, there is no movement of the fluid. And there is no obvious mixture between its particles or micelles. Only heat conduction caused by the movement of molecules between the fluid and the wall surface appears to exist. Actually, due to the temperature difference between the wall and the fluid, fluid flow near the wall will produce natural convection. The heat transfer process between heavy oil and water, or between water and wall, is not simple heat conduction in a static state or a laminar flow, but heat conduction and convection coexisting in two ways.

1 Heat conduction model of Heavy oil

Heat conduction means that heat transmission depends on micro movement of particle within objects rather than macro mixing movement, and heat must transfer from high temperature area to low temperature area. Heat conduction model described by Fourier law: 


$$
Q_{\text {oil-cd }}=q_{\text {oil }} A=-\lambda_{\text {oil }} \frac{\partial t}{\partial n} A
$$

Where $Q_{\text {oil-cd }}$ is heat conduction of oil. $q$ is density of heat flow, and unit is $\mathrm{W} / \mathrm{m}^{2}$. $\partial t / \partial n$ is normal temperature gradient, and unit is ${ }^{\circ} \mathrm{C} / \mathrm{m}$. $\lambda$ is thermal conductivity coefficient at temperature $t$, and unit is $\mathrm{W} /\left(\mathrm{m} .{ }^{\circ} \mathrm{C}\right)$. Of course, there are many factors that have influences on thermal conductivity $\lambda$, such as object composition, structure, temperature, humidity, pressure and state of aggregation and so on.

2 Thermal convection model of Heavy oil

Convection heat transfer is caused by macro movement of particle in fluid. When there is the temperature difference between solid wall and its adjacent fluid, as a result of micro group fluid, heat exchange occurs between the wall and the fluid. Convection heat transfer can be made of Newton's law of cooling [2]:

$$
Q_{\text {oil }-c v}=q_{\text {oil }} A=\alpha_{\text {oil }}\left(T_{w}-T\right) A
$$

Where, $Q_{\text {oil-cv }}$ is heat convection of oil, $\alpha_{\text {oil }}$ is heat transfer coefficient of heavy oil $\left(\mathrm{W} /\left(\mathrm{m}^{2} .{ }^{\circ} \mathrm{C}\right)\right)$. $T_{w}$ is sensor temperature. $T$ is average temperature of fluid cross section. $\rho$ is liquid density. $\mu$ is fluid viscosity, $c_{p}$ is specific heat capacity. $\mu$ is flow rate of the forced convection and $d$ is tube diameter. $\alpha$ is heat transfer coefficient, and unit is $\mathrm{W} /\left(\mathrm{m}^{2} .{ }^{\circ} \mathrm{C}\right)$. Since heavy oil is high viscosity fluid, and its viscosity is $1.2852^{*} 10^{4} \mathrm{mPa}$.s at $70^{\circ} \mathrm{C}$. Its density is close to water, specific heat capacity $c_{p}$ is $2 \mathrm{~kJ} /\left(\mathrm{kg} .{ }^{\circ} \mathrm{C}\right)$ [3]. So coefficient of heat transfer is [4]:

$$
a_{\text {oil }}=0.027 \frac{\lambda}{d}\left(\frac{\rho d u}{\mu}\right)^{0.8}\left(\frac{c_{p} \mu}{\lambda}\right)^{0.33}\left(\frac{\mu}{\mu_{W}}\right)^{0.14}
$$

\section{Heat conduction model of water}

The heat transfer model of water is consistent with the model of oil. But the thermal conductivity of water is different from that of oil.

$$
Q_{\text {water-cd }}=q_{\text {water }} A=-\lambda_{\text {water }} \frac{\partial t}{\partial n} A
$$

Where, $O_{\text {water-cd }}$ is heat conduction of water. The heat conduction coefficientis of water is increasing with temperature, whose variation range is between 0.60 to $0.67 \mathrm{~W} /\left(\mathrm{m} .{ }^{\circ} \mathrm{C}\right)$ from $20^{\circ} \mathrm{C}$ to $70^{\circ} \mathrm{C}$. Heavy oil heat conduction coefficient is similar to water, but the growth rate is relatively slow. From $20^{\circ} \mathrm{C}$ to $300^{\circ} \mathrm{C}$, the coefficient is between 0.1196 and $0.1650 \mathrm{~W} /\left(\mathrm{m} .{ }^{\circ} \mathrm{C}\right)$ [3]. Oil heat conduction coefficient is estimated by interpolation to $0.1277 \mathrm{~W} /\left(\mathrm{m} .{ }^{\circ} \mathrm{C}\right)$ at temperature $70^{\circ} \mathrm{C}$. The heat flow density of water is 5.2467 times as many as oil on the same condition.

4 Water heat convection model

The heat transfer convection model of water is consistent with the model of oil. But the heat transfer coefficient of water is different from that of oil.

$$
Q_{\text {water-cv }}=q_{\text {water }} A=\alpha_{\text {water }}\left(T_{w}-T\right) A
$$

Water viscosity in the $70^{\circ} \mathrm{C}$ is $0.4061 \mathrm{mPa}$.s. Specific heat $c_{p}$ is about $4.2 \mathrm{~kJ} /\left(\mathrm{kg} .{ }^{\circ} \mathrm{C}\right)$, the heat convection coefficient of water is calculated by formula 6 :

$$
a_{\text {water }}=0.023 \frac{\rho^{0.8} c_{p}^{0.4} \lambda^{0.6}}{\mu^{0.4}} \times \frac{u^{0.8}}{d^{0.2}}
$$

The convection coefficient of water is 437.9199 times as many as that of oil. Thus in the process the water heat convection flux is also 437.9199 times as many as that of oil.

\section{Heat transfer rate model}

The electrical resistance of metallic platinum varies with temperature. Platinum which has on good reproducibility and stability doesn't occur physical or chemical changes with temperature rising or degrading. By means to the function relationship of its resistance and temperature, platinum resistance temperature sensor detects the medium temperature. Its measurement result has on high accuracy, good stability and wide range of applications. We choose platinum resistance 
temperature sensor to measure the heat transfer rate of water and heavy oil [5].

The heat transfer of heavy oil and water within the storage tank is mainly composed of heat conduction and heat convection. Meanwhile, the heat transfer rate of heavy oil and water is determined by the amount of heat conduction and convection per unit time, and it can be calculated by the following formula:

$$
\frac{\partial \mathrm{T}}{\partial t}=\frac{Q}{\rho c}=\frac{Q_{c d}+Q_{c v}}{\rho c}
$$

Where, $Q_{c d}$ is heat conduction, $Q_{c v}$ is heat convection .

The ratio of water and heavy oil heat transfer rate is calculated by formula 8[6]:

$$
\frac{\partial \mathrm{T}_{\text {water }}}{\partial t_{\text {water }}} / \frac{\partial \mathrm{T}_{\text {oil }}}{\partial t_{\text {oil }}}=\frac{Q_{\text {water-cd }}+Q_{\text {water-cv }}}{\rho_{\text {water }} C_{\text {water }}} / \frac{Q_{\text {oil-cd }}+Q_{\text {oil-cv }}}{\rho_{\text {oil }} C_{\text {oil }}}
$$

Here, $\rho_{\text {water }}$ is the density of water, is equal to $1 \mathrm{~g} / \mathrm{cm}^{3} . c_{\text {water }}$ is the specific heat capacity of water, is equal to $4.2^{*} 10^{3} \mathrm{~J} /\left(\mathrm{kg}\right.$. $\left.{ }^{\circ} \mathrm{C}\right)$. $\rho_{\text {oil }}$ is the density of heavy oil, greater than 0.943 and less than 1 $\mathrm{g} / \mathrm{cm}^{3} . c_{\text {oil }}$ is the specific heat capacity of heavy oil, about $2 * 10^{3} \mathrm{~J} /\left(\mathrm{kg} .{ }^{\circ} \mathrm{C}\right)[3]$.

$Q_{\text {water-cd }}$ is nearly 5.2467 times as many as $Q_{\text {oil-cd }}, Q_{\text {water-cv }}$ is nearly 437.9199 times as many as $Q_{o i l-c v}$, The radio of heat transfer rate is in formula 9:

$$
\frac{\partial \mathrm{T}_{\text {water }}}{\partial t_{\text {water }}} / \frac{\partial \mathrm{T}_{\text {oil }}}{\partial t_{\text {oil }}}=\frac{2.62 Q_{\text {oil }-c d}+218.96 Q_{\text {oil }-c v}}{Q_{\text {oil }-c d}+Q_{\text {oil }-c v}}
$$

The rising rate of temperature in water is much higher than that in heavy oil. Platinum resistance temperature sensor is sensitive to temperature change. The heating rate of oil-water mixture can be measured by the sensor. The heating rate at each position is varied, so the oil water interface can be determined.

\section{Thermal conductivity under the condition of constant temperature}

In order to detect the thermal conductivity difference between heavy oil and water at constant temperature condition, three test tubes are heated in the visual temperature controller, which contain heavy oil, oil mixture and water respectively. Visual temperature controller can maintain constant temperature through electric mixer. Temperature control precision cab be reached to $\pm 0.1^{\circ} \mathrm{C}$. Experiment temperature reached to $60^{\circ} \mathrm{C}, 65^{\circ} \mathrm{C}, 70^{\circ} \mathrm{C}$ and $75^{\circ} \mathrm{C}$ respectively. Temperature changing process of two test tubes containing oil and water under above temperatures is measured by platinum resistance temperature sensor. Temperature data is gathered and calculated.

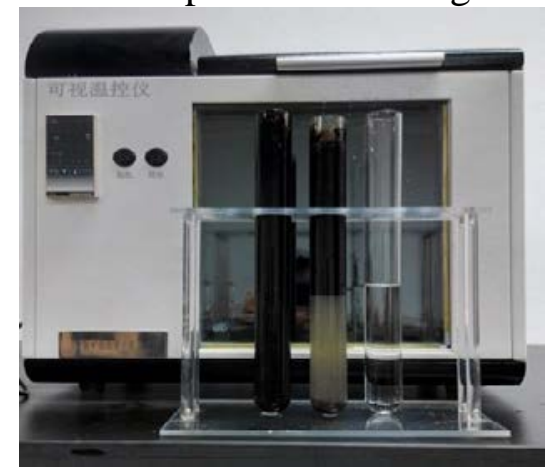

Fig.1. Experimental apparatus for oil / water heat transfer detection

Experimental process is shown in Fig.1. Visual temperature controller is heated from room temperature to $60^{\circ} \mathrm{C}$. Platinum resistance sensor measures temperature of each tube. The temperature changing curves of the two tubes are showed in Fig.2(a). Visual temperature controller is heated from room temperature to 65,70 and $75^{\circ} \mathrm{C}$, corresponding temperature changing data curves of tubes are showed in Fig.2(b), Fig.2(c), and Fig.2(d).

The rising rate of water temperature is faster than that of oil as shown in the Fig.2. 


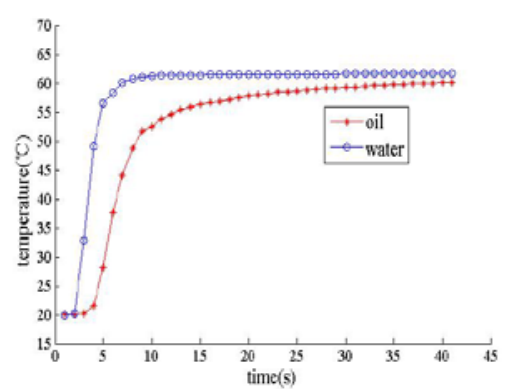

(a) The temperature curve at $60^{\circ} \mathrm{C}$

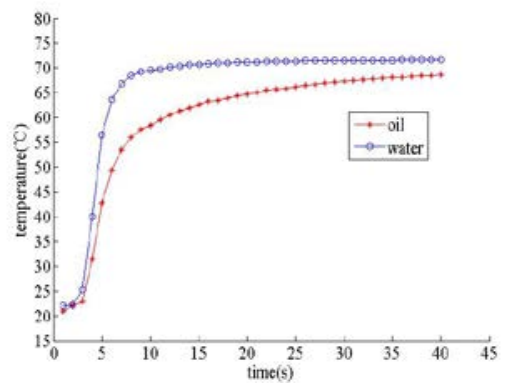

(c) The temperature curve at $70^{\circ} \mathrm{C}$

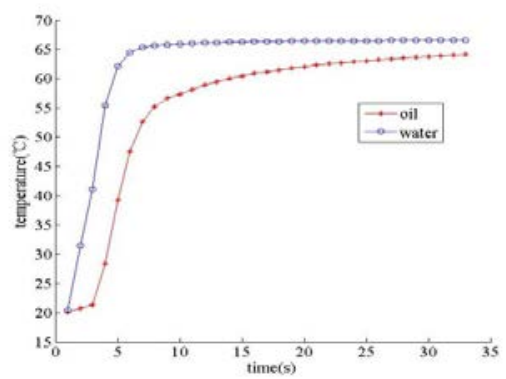

(b) The temperature curve of $65^{\circ} \mathrm{C}$

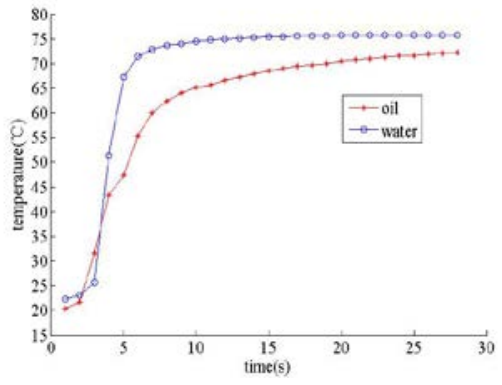

(d) The temperature curve at $75^{\circ} \mathrm{C}$

Fig.2. The temperature curve

From the Fig.2(a) to Fig.2(d), the heat transfer rate is calculated from the temperature data. Each adjacent temparature data is calculated by means of differential method. The heat transfer rate in the sampling time interval are expressed in the Fig.3(a) to Fig.3(d). At the beginning of the detection, heat transfer rate of water is rapidly falling. The heat transfer rate of the oil is slower than that of water.

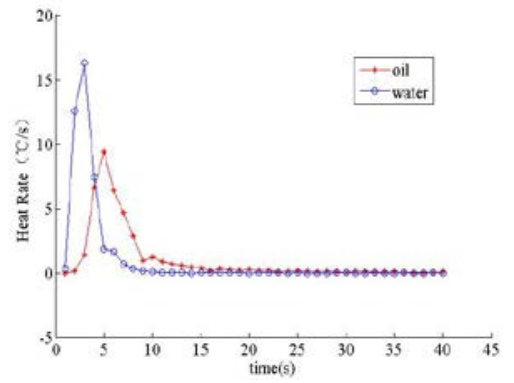

(a) The heating rate change at $60^{\circ} \mathrm{C}$

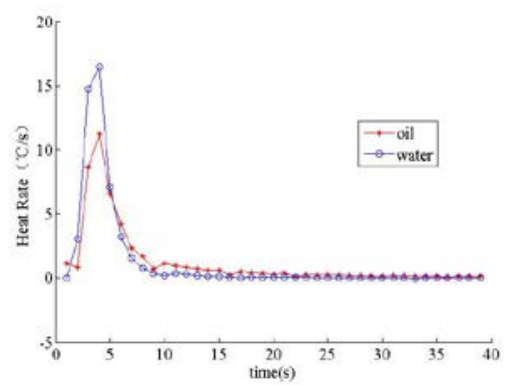

(c) The heating rate change at $70^{\circ} \mathrm{C}$

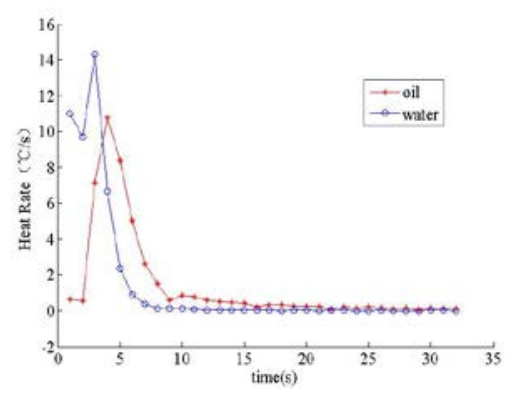

(b) The heating rate change at $65^{\circ} \mathrm{C}$

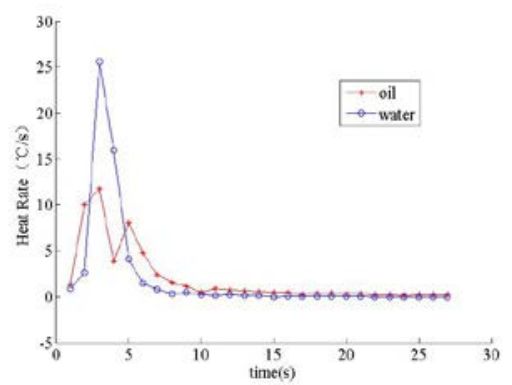

(d) The heating rate change at $75^{\circ} \mathrm{C}$

Fig.3. The heating rate change

Oil and water are heated to the above temperatures at the same conditions. When thermal equilibrium state is reached, the average heat transfer rate of the oil and water is shown in Table 1.

Table1 Heating Rate Table of Water/ Oil

\begin{tabular}{cllc}
\hline Temperature & Water & Oil & Ratio of water and oil heating rate \\
\hline 60 & 1.018 & 0.569 & 1.780 \\
65 & 1.399 & 0.496 & 2.821 \\
70 & 1.238 & 0.474 & 2.612 \\
75 & 1.909 & 0.392 & 4.870 \\
\hline
\end{tabular}

The experimental results are shown that, the higher the temperature is, the greater the difference 
between the water and the oil to reach the thermal equilibrium state. The effect of heat convection transfer increases with temperature rising. By means of to the difference of heat transfer rate of oil and water, the position of the oil water interface of the second tube which contains water and oil mixture in Fig.1 can be detected automatically.

\section{Conclusion}

In the process of heat transfer between the oil and water, heat conduction and heat flow of water is greater than that of oil. With the increase of temperature, the effect of heat convection increases. Heat transfer efficiency of water is higher, and heat transfer rate of water is faster. Detecting oil-water mixture temperature by platinum resistance sensor, The heating rate of water is faster than that of oil. Oil water interface was determined by detecting temperature rising rate within different positions. Through comparison experiment, the temperature changing between heavy oil and water temperature is detected, and accurate oil water interface is obtained.

\section{References}

[1] Yongsheng Qi, Shengkui Song, Yaqing Tu. Current situation and trend of development of oil tank level measurement technology[J]. Petroleum engineering construction, 2006,32(4) .

[2] Tao Chen, Guoliang Zhang. Transfer of chemical process[M].Beijing: Chemical Industry Press,2005:123-127.

[3] Xin Wang, Fajun Zhao,Jiang Liu, Longri Tan. Specific heat capacity and thermal conductivity of heavy oil viscosity-temperature property parameters change research[J]. Chemical science and technolog, 2012,20(3).

[4] Minheng Chen, Dezi Cong, Tunan Fang, Mingzhai Qi. The principle of Chemical Engineering[M].Beijing: Chemical Industry Press, 1999:229-252.

[5] Jietian Zhang, Hongbo Jia, Lei Ren. The natural effect of platinum resistance temperature sensor[J]. Sensor technology,2002,21(12).

[6] Vaziri H H.Coupled fluid flow and stress analysis of oil sands subject to heating[J].Journal of Canadian Petroleum Technology,1988,27(5):84-91. 